\title{
Influence on Chronic Venous Insufficiency of Primary Absence of the Great Saphenous Vein in the Saphenous Compartment at the Thigh
}

\author{
Pittaluga P.1,2, Chastanet S., ${ }^{1,2}$ \\ ${ }^{1}$ Riviera Veine Institut, Nice, France. \\ ${ }^{2}$ Riviera Veine Institut-IM2S, Monte-Carlo, \\ Monaco. \\ E-mail: paulpittaluga@hotmail.com
}

Pittaluga, P.; Chastanet, S. 2013. Influence on Chronic Venous Insufficiency of Primary Absence of the Great Saphenous Vein in the Saphenous Compartment at the Thigh, p.59. In: Bastos, Francisco Reis. Anais do V Simpósio Internacional de Flebologia [Blucher Medical Proceedings n.1 v.1]. São Paulo: Blucher, 2014

http://dx.doi.org/10.5151/medpro-flebo-SIF_35

\section{Background}

In patient with no history of saphenous ablation the absence of the great saphenous vein (GSV) within the saphenous compartment in a intrafascial situation at the thigh (SCT) is not rare. However it is unclear if this anatomic situation has an influence on the hemodynamic and clinical status of the patients with chronic venous insufficiency.

\section{Material and Method}

We reviewed the clinical, anatomical and hemodynamic data of patients whom consulted in our center between January 2010 and July 2012 and whom never had any saphenous ablation procedure. We considered two different anatomic situations:

- absence of the GSV within the SCT below the upper third of the thigh (GSV1);

- presence of the GSV within the SCT below the upper third of the thigh (GSV2).

We also reviewed the treatments performed and the number of zones treated by phlebectomy (NZT) in these patients.

\section{Results}

We included in the study 1,433 patients among whom 1,950 lower limbs were assessed for signs or symptoms of venous insufficiency. A GSV1 was present at least in one LL in 208 patients (14.5\%) and it concerned 299 LLs (15.3\%). Patients with GSV1 were younger (47.4 vs 50,0 yrs $P<.05$ ) and had a higher BMI (27.8 than $24.6 \mathrm{P}<.05)$ than patients with GSV2. In presence of varicose veins with GSV1 the frequency of C3 and C4 was higher (16.1\% and $6.2 \%$ vs $8.1 \%$ and $2.4 \% \mathrm{P}<.05$ ), the presence of symptoms was more frequent ( $81.0 \%$ vs $55.3 \% \mathrm{P}<.05)$, the sapheno-femoral junction was more frequently refluxing $(66.7 \%$ vs $30.1 \% \mathrm{P}<.05)$ and as well as the upper third of the GSV $(95.2 \%$ vs $69.1 \% \mathrm{P}<.05)$ with a larger mean diameter (7.6 vs 5.0 $\mathrm{P}<.05)$. A saphenous ablation by stripping or radiofrequency was more frequently carried out in LLs with GSV1 than in LLs with GSV2 (22.3\% vs $6.0 \%$ $\mathrm{P}<.05)$ with a higher NZT (7.0 vs $6.2 \mathrm{P}<.05)$. 


\section{Conclusion}

We observed that the absence of the GSV in the saphenous compartment at the mid-thigh was associated with a younger age and a higher BMI, with a higher frequency of symptoms, edema and skin changes in patients with chronic venous insufficiency. This anatomic situation was also correlated with a worse hemodynamic and anatomical status of the proximal GSV, leading to a more frequent saphenous ablation in patients with varicose veins.

Key words: CVI, saphenous vein, saphenous comportament. 